\title{
Las colecciones documentales de Segurola y Araujo y las representaciones del pasado en Buenos Aires (1780-1854)
}

The documentary collections of Segurola and Araujo and the representations of the past in Buenos Aires (1780-1854)

\section{Lucas Angueira}

Instituto de Estudios Históricos - Universidad Nacional de Tres de Febrero, Argentina

lucas.angueira@gmail.com

\section{Resumen:}

En este artículo se estudia la práctica coleccionista de documentos de Saturnino Segurola (1776-1854) y José Joaquín de Araujo (1772-1835) en Buenos Aires en las primeras décadas del siglo XIX con el objetivo de analizar su relación con algunas representaciones del pasado realizadas en ese período. Se observará cómo en esta práctica influía el empirismo, se estudiará el abordaje crítico a los documentos y se indagarán las relaciones entre estas prácticas y la política. Si bien se percibe una continuidad epistemológica en todo el período esta práctica se vio impactada por el contexto político.

Palabras clave: Archivo, Colecciones, Empirismo, Crítica, Representaciones del pasado.

\section{Abstract:}

This article studies Saturnino Segurola (1776-1854) and Joaquín de Araujo's (1772-1835) collecting of documents in Buenos Aires in the first decades of the 19 th century, with the aim of analysing its function in some representations of the past produced in that period. It will be observed how empiricism influenced this practice for the production of knowledge, and the critical approach to documents that the actors made will be analysed. Even though there is an epistemological continuity throughout the whole period, this practice was influenced by the political context.

KEYwoRDs: Archive, Collections, Empiricism, Criticism, Representations of the past.

\section{INTRODUCCIÓN}

A inicios de la segunda mitad del siglo XIX algunos historiadores rioplatenses atravesaron un período en el que creyeron conveniente la recolección y acumulación de materiales para el "historiador futuro" (Wasserman, 2008, pp. 63-90). La publicación de La revista de Buenos Aires es quizá uno de los más interesantes modelos de ese momento. A modo de ejemplo: en el primer párrafo del primer texto del primer número de esta revista, salido de la imprenta en mayo de 1863, se incluye la idea de que los datos sobre la historia del puerto de Buenos Aires que se reúnen en allí "podría servir de base para levantar sobre él la historia del pueblo argentino" y más adelante que ese texto se trata de una "colección de materiales que ofrecemos al historiador futuro" (Trelles, 1863).

En esa revista, que se planteaban como objetivos la recolección documental y el salvar de la pérdida valiosos materiales, son recurrentes los nombres del clérigo Saturnino Segurola (1776-1854) y de José Joaquín de Araujo (1772-1835) ${ }^{1}$. Estos dos sujetos habían reunido diversos materiales sobre el pasado rioplatense en las décadas precedentes y es por ello que Vicente Quesada, Manuel Trelles y otros publicistas que intervinieron en la mencionada revista hicieron foco en ellos después de su muerte. Estas colecciones particulares se componían de papeles sueltos, manuscritos, impresos de diverso tipo, libros y objetos materiales del pasado. 
En este artículo se estudiará esta práctica coleccionista, haciendo foco en la acumulación de fuentes documentales y libros, con el objeto de analizar su utilización en la producción de representaciones del pasado realizada por estos letrados y por otros que se apoyaban en su acervo, en las que se colocaba al empirismo y al abordaje crítico ${ }^{2}$ de los documentos en un lugar central. Sobre esta idea se despliega nuestra mirada.

En relación a este abordaje se intenta estudiar cómo este coleccionismo -y los escritos sobre el pasado asociados a él- estaban íntimamente relacionados con diversos cambios políticos, como la sociabilidad letrada que comenzaba a operar en la Buenos Aires de ese período (González Bernaldo, 1991). También se observan nexos con numerosas pujas políticas que se producían en esa ciudad, en la región rioplatense, en la totalidad de la monarquía e incluso fuera de ella, con una clara continuidad tras el período de revolución y guerra. Para ello se parte de nuevas miradas de la historia política al Imperio español, de propuestas de la sociología de la ciencia y de aportes de la historia cultural.

Sería posible trazar una línea recta entre los esfuerzos coleccionistas de principios del siglo XIX y las recopilaciones de La revista de Buenos Aires, en las que ambas resulten dos hitos en la historiografía nacional argentina. Incluso se podría los observar como parte de una misma práctica de acumular materiales para salvarlos de la pérdida o el olvido en dos períodos. Pero como se verá, ambas representan momentos diferentes entre sí: lejos de resultar una "práctica sin discurso", como señala Fabio Wasserman (2008) para las colecciones de la segunda mitad del siglo XIX, es decir "una práctica erudita pero desligada de un discurso capaz de dotar de sentido al pasado" ${ }^{3}$, a principios del mismo siglo Segurola y Araujo eran dos de los letrados interesados en intervenir discursivamente en un contexto de crisis monárquica a partir de la utilización de papeles del pasado. Su práctica coleccionista adquiría una pragmática particular: dotar de significado al pasado con el objetivo de intervenir políticamente en el presente.

Si bien sus colecciones continuaron aumentándose y utilizándose hasta que tras sus muertes (ocurridas en 1854 y 1835 respectivamente) se derivaron sus materiales a otros repositorios o se perdió su rastro, ambos individuos van a encontrar el punto más significativo de su intervención en el espacio público en las primeras cuatro décadas del siglo XIX, un período de reformas, tensiones políticas e incertidumbre en el Río de la Plata. Es en esas décadas cuando aportarían materiales para diversas representaciones del pasado (e incluso ellos mismos realizarían algunas). A su vez, ese período de intervención se encontrará partido por la ruptura del Imperio español.

Las actuaciones de Segurola y Araujo en ese período son dos de las más significativas en relación a la colección particular de documentos en la primera mitad del siglo XIX en Buenos Aires, sobre todo si se tiene en cuenta la extensión temporal de ambas y es por ello que se indagan sus trayectorias en este artículo. Su estudio permite observar el tránsito entre dos maneras diferentes de abordar esa práctica, marcadas por los cambios políticos ocurridos en la zona a partir de 1810. Además estos dos actores presentan diferencias entre sí que resultan significativas para indagar diversos aspectos: provienen de espacios de actuación diferentes (el primero del mundo eclesiástico, el segundo de la administración real), ambos tienen diferentes intereses respecto de sus colecciones y realizan diferentes acciones con ellas.

En este artículo se analizan algunas de las referencias a estas colecciones realizadas en diversos textos publicados a lo largo del siglo XIX como así también se estudian catálogos y cartas. Por otra parte, se observarán representaciones del pasado en las que se mencionaran estas colecciones o bien en las que se indica explícitamente que utilizaran como fuente documentos provenientes de estas colecciones en los años en que estuvieron en manos de Segurola y Araujo, sea por parte de sus formadores o por otros actores que recurrieran a ellas. Todas estas fuentes se hayan en libros, revistas y periódicos publicados en un arco temporal que abarca desde principios del siglo XIX hasta mediados del siglo XX. 


\section{ERUDICIÓN COLECCIONISTA, EMPIRISMO Y CRÍTICA EN LAS REPRESENTACIONES DEL PASADO}

El siglo XVIII trajo con sigo nuevas maneras de representar el pasado y estas nuevas representaciones se vieron acompañadas de nuevas pragmáticas. En los siglos XVI y XVII fueron los cronistas quienes produjeron relatos de la conquista y fundación de poblaciones y ciudades. Más tarde los jesuitas como Nicolás del Techo, José Guevara y Pedro Lozano recopilaron esos testimonios y sumaron información proveniente de documentos para escribir sus historias, aunque esto último se presuma a partir de referencias de terceros ya que no citaban textualmente la información en sus textos ni colocaban referencias de sus fuentes (Carbia, 1939, p. 45; Esteve Barba, 1964, pp. 577-592).

A diferencia de los cronistas e historiadores jesuitas, los letrados ilustrados en sus representaciones del pasado que comenzaron a realizar en el último tercio del siglo XVIII añadieron una mayor erudición: la documentación ocupaba un lugar central y las fuentes bibliográficas son incorporadas a los textos a partir una lectura crítica. Estos serán requisitos ineludibles para la aceptación de cualquier discurso público sobre el pasado por parte de aquellos sujetos habituados a leer textos históricos.

En los debates de esta época, como los suscitados alrededor de la creación del Archivo General de Indias, se muestra una de las constantes de la renovación que la Ilustración y el empirismo aportaron a las representaciones del pasado, ya que los actores intervinientes, al margen de sus intencionalidades políticas o su lugar de proveniencia, estimaron necesario revisar las historias realizadas hasta ese momento a la luz de nuevas maneras de estudiar las fuentes (Cañizares Esguerra, 2007). Este aspecto de la epistemología dieciochesca se plasma en el celo con que los letrados citaban documentación de forma textual o con una referencia a pie de página en la que se indicaba al lector donde encontrar ese dato en los archivos. También se utilizará como herramienta el entrecruzamiento de autores como un medio para indicar la verosimilitud de la información proveniente de trabajos históricos precedentes. Este punto es fácilmente confundible con las prácticas historiográficas románticas, e incluso, con las positivistas, como ocurre en un trabajo de David González Cruz (2017). En realidad es la aplicación a la historia de una práctica habitual en otros saberes que se venía construyendo en Europa desde el siglo XVII: el empirismo (Shapin y Schaffer, 2005).

Estos letrados se encontraban familiarizados con el empirismo debido a la ausencia de especificidad disciplinar, que permitía a un mismo sujeto dedicar su tiempo a actividades que -desde la separación tajante entre áreas del saber que operó paulatinamente desde la segunda mitad del siglo XIX-, serían consideradas incompatibles (Mazin, 2008, p. 53). De este modo, diversos actores implementaron el método empírico como instrumento de probación de sus observaciones del pasado. Y los experimentos son un ejercicio político (Shapin y Schaffer, 2005), por lo que es necesaria la sociabilidad para que los diversos participantes consientan que una afirmación sobre lo estudiado, en base a lo demostración empírica, es aceptable. Ya no basta la sola legitimidad del actor que la proponga. Las propuestas son aceptadas en tanto y en cuanto cualquier par pueda participar o repetir el experimento. Para ello podrían ofrecerse diversos caminos: la demostración presencial, el montaje de novedosas tecnologías literarias que permitían (mediante descripciones o gráficos) la reproducción a distancia de los experimentos o bien mediante el aporte de elementos materiales.

En todos los casos se trata del mismo mecanismo: luego de la investigación y el hallazgo resultaba ineludible la probación, necesaria para participar de la evidencia al lector que le resultara inaccesible participar con sus sentidos del experimento. Esta innovación epistemológica en el Río de la Plata inauguró una larga serie de representaciones del pasado. En este sentido publicaciones muy circuladas por la geografía del Virreinato del Río de la Plata como el Telégrafo Mercantil o la Guía de Forasteros (a los que se hará referencia más tarde) han sido vectores de transmisión de estos saberes y prácticas. Pero no solamente ellos: en el estudio de otros objetos, como en el naturalismo, operaba la misma práctica, por lo que su difusión fue fluida. Si alguna reflexión sobre cualquier aspecto de la naturaleza o de la sociedad (incluyendo a la historia) aspiraba a convencer, debía adecuarse al empirismo. 
Por citar un ejemplo, Gregorio Funes (1802) en el Telégrafo Mercantil, bajo el seudónimo de Patricio Saliano, criticó abiertamente en un extenso texto a los miembros del cabildo secular cordobés porque estos habían señalado en un texto anterior publicado en el mismo periódico aspectos del pasado urbano de Córdoba sin consultar la documentación que ellos mismos conservaban en el ayuntamiento. Funes se encargó de fundamentar sus dichos con bibliografía y con documentación del archivo. Es decir que para contradecir a los cabildantes, en un intento de ridiculizarlos, el clérigo cordobés sentó su argumentación en el hecho de que estos no habían ajustado su escrito a las reglas del empirismo y de la crítica. Detrás de ese señalamiento había otras intencionalidades: el deán pertenecía a una facción diferente a la de los miembros del cabildo secular, por un lado, y aspiraba a posicionarse como un escritor ilustrado en Buenos Aires, por otro. Sus motivaciones no se reducían exclusivamente al saber, también incluían asuntos políticos propios de la sociedad cordobesa de ese momento ${ }^{4}$.

En el naturalismo 5 dieciochesco se elegía describir hallazgos con el objetivo de que cualquier otro sujeto sea capaz de repetir la experiencia. Estas narraciones frecuentemente se acompañaban con ilustraciones, una herramienta útil y aceptada para sustentar discursos. Por otro lado intentaban, cuando era posible, trasladar ejemplares de lo encontrado para que otros actores puedan percibir las características de lo nuevo con sus propios sentidos. En las representaciones del pasado la experimentación se presentaba de una forma más compleja, debido a las características de lo estudiado, difícil de ser mostrado por fuera del discurso ${ }^{6}$. Es posible observar en las fuentes que se aceptaba como contacto empírico con la historia la lectura de documentación. Esta experimentación, que se podría denominar simple, ocurría cuando el actor tomaba contacto con la fuente y volcaba sus observaciones en un escrito. Esta era una práctica habitual, incluso entre los cronistas e historiadores jesuitas (Carbia, 1939).

Pero los modos transigidos colectivamente en siglo XVIII para representar el pasado exigían que otros sujetos también participen del experimento. Para ello debía brindarse evidencia: se observa la necesidad de incluir citas textuales de documentación o brindar referencias acerca de dónde encontrar ese documento en los archivos. A partir de allí la experimentación comenzaba a duplicarse: el historiador recolecta la muestra del pasado y realiza su exégesis, pero debe permitir que el lector también se contacte con lo que él observa y pueda de igual forma verificarlo. De ese modo se clausuró la posibilidad de sustentar afirmaciones del pasado sobre el supuesto de la autoridad del intérprete. Ya no importaba si este era un noble, un magistrado o un plebeyo: pesaba más la práctica empírica.

El carácter del empirismo en esta área del saber es aún más complejo. No solamente era exigible que el historiador tomara contacto con la fuente y que luego permitiera al lector hacer lo propio: la experiencia era un requisito que corría incluso para a las fuentes. Comienza en esta época a valorarse en mayor medida el texto producido en lugar y la época de los hechos que se documentan por sobre aquellos que se produjeran más tarde. Del mismo modo será más valiosa aquella fuente que haya sido redactada por los actores intervinientes en los acontecimientos, como protagonistas u observadores directos, por sobre aquellos que cristalizaran contemporáneamente experiencias ajenas. En ese sentido, la experiencia se triplica. Allí, creemos, radica la innovación del siglo XVIII aportada a las reflexiones del pasado y a la crítica documental: estas podrían realizarse mediante una experimentación orientada en varios sentidos, como se observa en los casos que se presentan en este trabajo.

Este mismo criterio entrará en juego también para la utilización de bibliografía: se valorará aquella que cuente con autoridad empírica: las crónicas serán más valiosas si fueron escritas de forma contemporánea e in situ, los trabajos de historiadores serán juzgados por la presencia o no de documentos originales, etcétera. A partir de esas necesidades se montarán las exigencias críticas de actores como Funes o Araujo -como se veráa sus interlocutores. Para los letrados del último tramo del siglo XVIII y de principios de la centuria siguiente el empirismo abrió la posibilidad concreta de producir conclusiones originales y novedosas sobre el pasado. Y sobre ese empirismo es que se comenzará a desarrollar la práctica (que se volverá cada vez más frecuente con el correr del siglo XIX) del coleccionismo documental. 
De las dos trayectorias que acompañan este artículo, la única que incluye -además de coleccionismorepresentaciones del pasado producidas y publicadas con el objetivo de intervenir en el debate público, es la de José Joaquín de Araujo. Los escritos más relevantes en ese sentido vieron la luz en la primera década del siglo XIX: su intervención en el Telégrafo Mercantil en 1802, la Guía de Forasteros de 1803 y las Adicciones y correcciones de 1807, todas ellas bajo el seudónimo de "Patricio de Buenos Ayres" o "Un Patricio". Segurola, como se mencionó, era más reacio a publicar sus reflexiones, pero sí colaboró activamente en empresas de otros sujetos.

En el primero de sus textos Araujo responde a Eugenio del Portillo, quien a su vez, bajo el seudónimo de Enio Tullio Grope, había publicado una respuesta a un almanaque que había publicado Juan de Alsina ${ }^{7}$. Se analizarán algunos aspectos de esos textos para observar cómo los documentos empiezan utilizarse no solo como fuente de información sino además como herramientas epistemológicas y retóricas en las representaciones del pasado.

Del Portillo había señalado, a partir de la consulta de "los voluminosos papeles originales que existen custodiados en su primitiva arquita en la casa de D. Joseph Justo de Garay [...] único descendiente por línea recta viril de aquel memorable fundador de Buenos-Ayres" (1801, p. 75), que la fundación de Buenos Aires se había producido en 1575, hecho que podría confirmarse, también, consultando otros papeles pertenecientes a otros conquistadores y en documentos enviados al "Archivo del Real y Supremo Consejo de Indias, y [...] Actas Capitulares de Buenos Ayres” (1801, p. 75). En ellos se había basado, según Portillo, el jesuita Guevara en su Historia.

Araujo despliega su erudición para contestar a Del Portillo: en primer lugar indica, como parte de su argumentación, que la dificultad de conocer el pasado en todo el mundo se "suplió por algunos genios atrevidos con la invencion de mil fabulas" (1802, p. 10). Luego, escribe, que "esta desgracia tambien ha alcanzado á la fundacion de las Provincias Argentinas, cuya Historia está casi desnuda de primitivos documentos que realizen sus verdaderos hechos" (1802, p. 10), con el objetivo de exculpar los errores de su interlocutor, al que juzga capacitado para el debate.

Las conclusiones sobre la fundación de Buenos Aires a las que aborda Araujo son diferentes: esta ciudad se había fundado "con alguna certeza" el 2 de febrero de 1535 (1802, p. 14). La ausencia de documentos originales no le permite abordar a resultados concluyentes y hace necesaria la lectura de otras fuentes, como crónicas e historias. El resultado ofrecido por Araujo surge de la lectura de ellas y para con ese objetivo adopta un criterio: serán válidas aquellas que basen su contenido en las afirmaciones de testigos presenciales en remplazo de las fuentes depositarias de los "verdaderos hechos" (1802, p. 14). Por ejemplo, considera que la fecha de la primera fundación de Buenos Aires presente en la historia de Guevara es más fiable que la del texto de Ruy Díaz de Guzmán “por tener á su favor la fé de testigos presenciales”. También considera más preciso el trabajo de Lozano, porque "siguiendo á Ulrrico Fablo Schmidel, que vino con Mendoza, señala la referida época, y es indubitable que debe ser preferible á Rui Diaz, que escribió de oidas tantos años después" (1802, p. 11).

Si bien para Araujo era importante reafirmar la fecha de la primera fundación como más relevante, por otro lado también objetará la afirmación de que la "reedificación" de la ciudad se había producido en 1575: "no debe dudarse que se verifico en el año de 1580, como consta por el testimonio de esta fundacion, que se reconoce à fol. 16 buelta del Libro n. ${ }^{\circ} 25$ en el Archibo de este Ilustre Cavildo" (1802, p. 17). Incluso Araujo ofrece al lector, en una extensa nota al final del texto, una transcripción textual de la fuente (1802, pp. 22-24).

Sin profundizar en el contenido de este debate y quién tendría argumentos más consistentes en él (incluso se publicó una respuesta de Eugenio del Portillo más tarde), resulta interesante cómo ambos actores recurren al empirismo como elemento central para fundamentar sus dichos. Y lo realizan a partir de esa experiencia triplicada que se señaló anteriormente: se exige experimentación al historiador como intermediario entre el autor de la fuente y el lector, también se le reclama experimentación al autor de la fuente y se le ofrece la participación en el experimento al lector, a partir de la transcripción de documentos, o bien otorgando 
la posibilidad de repetir la experiencia con la indicación del lugar de procedencia del dato para su posible consulta y revisión.

Es posible que al momento de participar de ese debate Araujo se encontrara trabajando en su Guía de forasteros $(1803)^{8}$ y por ello estuviese familiarizado con la documentación. Este texto, mucho más extenso que los anteriores, tiene características diferentes. Si bien tiene una gran cantidad de contenido histórico, en primer lugar no forma parte de ningún debate y en segundo es escrito desde la autoridad discursiva que brindaba la propia monarquía, ya que se trata de un encargo de las autoridades. Por lo tanto se puede sostener que hace un uso de las fuentes con un criterio más tradicional. Es decir, utiliza documentos con el objetivo de autorizar la información pero no realiza ninguna cita textual y son escasas las referencias heurísticas o bibliográficas. Es en sí misma la Guía un documento destinado a cualquiera que necesite información sobre el Virreinato del Río de la Plata.

Este impreso es una pintura del estado del virreinato en ese momento, tanto en el "estado político" como en el "estado eclesiástico" y en el "estado militar". En la primera parte se describen sus instituciones y funcionarios, sus intendencias, sus ciudades importantes (con su fecha de fundación, ubicación y blasones), clima, comercio y otros. En la segunda se mencionan los diferentes miembros de la jerarquía eclesiástica y las diferentes áreas en las que se dividía el ejercicio de la Iglesia en ese año. En la tercera se mencionan los diferentes cuerpos del ejército (en muchos casos se deja constancia de la fecha de fundación de estos) y los nombres de sus jefes.

Esta Guía de forasteros tuvo una gran recepción y si la pragmática pensada para el texto era erigirlo como fuente de información sobre del pasado y presente del área rioplatense por sobre otras fuentes anteriores, el objetivo fue logrado. Este texto fue citado como bibliografía durante todo el siglo XIX y solo se convertiría en "fuente histórica" cuando la profesionalización de la práctica historiográfica modificara los criterios para citar un texto historiográfico en plano de paridad. Vicente Quesada, por ejemplo, sostiene tras seis décadas de la publicación que "Esta Guía es muy estimada por los amantes de la historia nacional, contiene datos y noticias de sumo interés: hoy es una obra rara é importante, que puede consultarse con confianza" (Quesada, 1864, p. 456). Incluso el mismo Araujo, desde el anonimato, cita su propio trabajo: en 1807 publicó en un breve texto titulado "Adiciones y correcciones a la dedicatoria que el autor del romance heroyco sobre la Reconquista de Buenos-Ayres hizo al M.I. Cabildo” en el que recomendaba al clérigo Pantaleón Rivarola la lectura de su Guía para no incurrir en los errores históricos que le señalaba (Araujo, 1807, p. 5).

Tras la revolución y con los cambios en la experiencia histórica que trajo aparejados, surgieron nuevas formas de representar el pasado (Wasserman, 2016). En ellas Segurola y Araujo participarán de un modo diferente. Quizá el nuevo uso de las colecciones particulares de estos actores lo inaugure Gregorio Funes. El clérigo cordobés, muchas veces acusado de tomar información de diversas fuentes sin la correspondiente referencia (Carbia, 1921) en su Ensayo de la bistoria civil de Buenos Aires, Tucumán y Paraguay (1856) agradece a Segurola por su colaboración:

"nada iguala al deseo de este erudito eclesiástico, por enriquecer su espíritu de conocimientos útiles, sino su esquisita diligencia en adquirirlos. Sin perdonar gastos ni trabajos se ha formado una biblioteca de manuscritos escojidos, que aumenta de dia en dia. Asociadas nuestras tareas en la revision de los archivos públicos, y auxiliado de sus papeles fue que pude ponerme en estado de continuar mi obra" (1856, p. 5).

En el mismo párrafo también menciona la colaboración recibida de Araujo. Inclusive menciona la relevancia de su Guía de forasteros, a la que presenta como un texto reconocido públicamente:

"Debo también no pequeños servicios á D. José Joaquin de Araujo, [...], cuyo gusto por las antigüedades de las provincias y sus noticias históricas no es desconocido entre nosotros" (1856, p. 5). ${ }^{9}$

Otro caso, en consonancia al uso que le dio Funes a las colecciones documentales particulares -en este caso principalmente la de Segurola-, es el de la publicación de la Colección de obras y documentos relativos a 
la historia antigua y moderna de las provincias del Río de la Plata ${ }^{10}$ del napolitano Pedro de Angelis. Estos impresos, que vieron la luz en seis tomos entre 1836 y 1837, tenían como objetivo publicar por primera vez muchas obras inéditas e, incluso, participar del coleccionismo a otros sujetos que, a partir de la reproducción de imprenta, podrían iniciar sus propias colecciones.

En este trabajo el publicista europeo recopiló setenta textos de los cuales cincuenta y siete se publicaban por primera vez (Sabor, 1995, p. 308). Del total de escritos editados por de Angelis, trece provenían de la colección de Segurola, todos ellos publicados en los primeros cinco tomos. Esto coloca a Segurola en el lugar de más importante aportante a la colección impresa en los años rosistas.

Veinte años después de la aparición del trabajo de Funes, nuevamente aparecerán elogios públicos para la colección de Segurola y la generosidad de sus aportes. En el segundo tomo de la colección aparece una lista de suscriptores en el que figura el nombre del clérigo con un llamado a pie de página, único en toda la lista, en el que de Angelis señala "Si no nos hubiese retraido el temor de ofender [...] le hubieramos dado un lugar privilegiado en esta lista; por ser realmente, no un simple suscriptor de nuestra obra, sino el que la fomenta y protege" (De Angelis, 1836, p. 5).

Cada uno de los textos publicados por de Angelis estaba acompañado de un estudio introductorio en el que indicaba la proveniencia del documento entregado al lector. En estos prefacios, cuando se indicaba que el proveedor del documento era Segurola, el elogio era recurrente. Este solía incluir una adjetivación del canónigo ("generosidad", "celo ilustrado", "liberalidad y benevolencia”, entre otros) y un elogio a su colección ("riquezas literarias", "selecta biblioteca", entre otros) $)^{11}$.

Otro caso de aporte de Segurola es el realizado a Woodbine Parish. Este diplomático británico, miembro de la Royal Society, poseía un claro interés sobre el Río de la Plata (donde se desempeñó entre las décadas de 1820 y 1830) que lo llevó a establecer vínculos con letrados porteños y a reunir materiales que le permitieron escribir Buenos Ayres and the Provinces of the Rio de la Plata, libro que tiene dos versiones publicadas en Londres, la primera en 1838 y la segunda catorce años más tarde. Ambas tienen notables diferencias de contenido. De hecho, la segunda -realizada ante el renovado interés por el área rioplatense producido tras la caída de Juan Manuel de Rosas en febrero de 1852 (Wasserman, 2008, p. 54)-, introduce aspectos sobre el descubrimiento y la conquista de esta área de Sudamérica no tratados en el libro publicado en 1838. La de 1852 es la que más ha circulado, por el hecho de que se trata de la más amplia y por su casi simultánea traducción al castellano realizada por Justo Maeso publicada en Buenos Aires (Parish, 1852b).

Si se atiende el aspecto heurístico de las obras de Parish se encontrarán también diferencias: la primera versión fue realizada en paralelo a la paulatina publicación de la Colección de Pedro de Angelis (1836-1837). El británico considera a esta empresa editorial como "the most important and interesting publication which has a yet appeared in any of the new states of Spanish America” (Parish, 1838, p. 14) y señala que su aparición cambió los planes de su propio trabajo, transformándolo en un bosquejo general del área rioplatense en lugar de una recopilación documental. Mientras que la segunda versión del libro de Parish estará apoyada principalmente sobre la obra del napolitano, ese primer "general sketch" contará con otras fuentes: en las páginas iniciales señala que las dificultades que representaron para su trabajo el desorden y la pérdida de materiales del archivo que se produjeron tras 1810 fueron subsanadas por la colaboración de algunas pocas personas, entre las que destaca solamente a Saturnino Segurola (Parish, 1838, p. 4).

El clérigo porteño permitió que Parish utilice sus materiales, de los cuales el diplomático obtuvo copias. Incluso, señala que parte de la "considerable collection of MS"12 de mapas y papeles inéditos viajó con él cuando abandonó Buenos Aires en 1834, a partir de una compra. Si se observa el inventario de la colección de Segurola realizado tras su muerte ocurrida veinte años más tarde, se encuentra una copia de "Notice on the Megatherium by Woodbine Parish" (Biblioteca Nacional, 1940, p. 21), texto escrito a partir del fósil que Segurola le facilitó al británico en los años en que estuvieron relacionados entre sí en Buenos Aires (Podgorny, 2013, p. 15), aspecto que demuestra un fluido vínculo. 
Es notable la omisión a Segurola en la siguiente edición del libro de Parish. En el párrafo en el que se mencionaba al coleccionista rioplatense en la primera edición, en la segunda aparece modificado y la ayuda que atribuía a Segurola para la recolección de documentos originales se la asignará luego a la "kindness of individuals" (Parish, 1852, p. 30), volviendo anónima la relación con el eclesiástico. Incluso, si bien el nombre del clérigo es suprimido en toda la obra como fuente de información (solo se menciona su rol en la introducción de la vacuna al Río de la Plata), se sostiene, quizá por error, la sigla "MS"13 al realizar la referencia a un mapa copiado de la colección de Segurola (página 104 de la edición de 1838, página 165 de la edición ampliada de 1852).

Es posible que la invisibilización de Segurola en la segunda versión tenga que ver con el peso que ganó en ella la colección de Pedro de Angelis (que como vimos, se nutría en gran parte de la colección del clérigo). También se puede presumir que Parish haya querido enmendar una contradicción: en páginas subsiguientes condena el saqueo de los archivos públicos para alimentar colecciones privadas del extranjero (práctica de la que desliga a Segurola) y se muestra él mismo como un "profanador" o "exportador" de archivos. Una última interpretación de la omisión es que quizá Parish haya querido entregar al lector una referencia más concreta, proveniente de una obra impresa disponible en Londres (Sabor, 1995, p. 162) y no de un archivo privado y situado a miles de kilómetros de la capital británica.

\section{CONOCER, DOMINAR, COLECCIONAR: UNA CONQUiSTA SIMBÓLICA DEL NUEVO MUNDO}

El reformismo borbónico dieciochesco impulsó diversas empresas de exploración de sus territorios americanos. En una época en la que muchos concebían el presente del imperio en clave decadentista, los monarcas españoles (y en especial Carlos III) promovieron la creación de academias y espacios de acumulación de los objetos recolectados para su estudio o exhibición (museos, jardines botánicos, bestiarios) y el reconocimiento de la geografía del imperio, todos ellos con el fin de modificar virtuosamente la realidad. En este contexto se realizaron diversas expediciones a América para inspeccionar la naturaleza. Estos viajes tenían, además del impulso de la curiosidad, objetivos políticos y económicos (Nieto Olarte, 2003).

Son conocidos los casos de las expediciones encabezadas por Alejandro Malaspina y Alexander von Humboldt, entre otras ${ }^{14}$. En el área meridional americana existieron diversas empresas similares, que fueron estudiadas por Marta Penhos en Ver, conocer, dominar (2005). En las entradas al Chaco Gualamba y, principalmente, en la Comisión Demarcadora de Límites que se envió con el objetivo de delimitar la frontera entre las posesiones españolas y portuguesas en América, trabajaron diversos actores encargados de recolectar materiales e información. Estos produjeron gran cantidad de escritos en los que se solapan saberes sobre animales y vegetales, sobre las características del terreno, sobre la población originaria, sobre la economía, política y sociedad de los pueblos de origen europeo y sobre el pasado (Penhos, 2005, p. 127).

Estos viajes a lo desconocido también tenían su paso por lo conocido, es decir, por las diversas ciudades y campañas. Muchos viajeros aprovecharon esa oportunidad para recorrer archivos en búsqueda de información necesaria para sus trabajos, como en el caso de Félix de Azara. Este acercamiento a las ciudades de los miembros de la comisión tuvo un importante impacto en la producción de saberes rioplatense: con ellos llegaron diversos instrumentos (De Asúa, 2010, p. 73) para la indagación de la naturaleza y también se produjo una transmisión de técnicas y saberes sobre cómo estudiarla, a partir del contacto directo entre europeos y locales o a partir de la reproducción de trabajos en los periódicos de Buenos Aires a partir de 1801.

También, a partir de este acercamiento, se incorporaron prácticas en la cultura de la ciudad de Buenos Aires. Diversos actores locales comenzaron a recolectar materiales de diversa índole: restos animales, vegetales, ejemplares minerales, documentos, libros y otros. Según Rómulo Carbia (1939, pp. 55-65) esta práctica local nació de la imitación del accionar de los peninsulares de la Comisión. El inventario de la colección de Segurola 15 realizado tras su muerte permite apoyar esta hipótesis: muchos de sus papeles 
provenían de esa empresa. Su etapa de juventud, además, coincide con la época en la que Azara y otros deambulaban por el área rioplatense.

De todos modos no se puede observar esta incorporación de prácticas y saberes como una recepción pasiva, un "trasplante cultural" como señalara Guillermo Furlong (1969): estos actores buscaban hacerse de saberes, de ideas, de técnicas, de instrumentos, pero también aspiraban a realizar sus aportes. Los letrados rioplatenses escribían historia (e indagaban la geografía y la naturaleza) como súbditos del monarca pero también como habitantes de una ciudad que tenía intereses corporativos, que en ocasiones no se condecían con los intereses de otras ciudades o los de la metrópoli.

Desde la perspectiva de la monarquía policéntrica ${ }^{16}$ se puede percibir al Imperio español como una extensa red de ciudades, tal como lo hizo José Luis Romero (2014, p. 12), en la que existían diversos tipos de solidaridades pero también tensiones y pujas de intereses. Las representaciones del pasado, de la naturaleza y la geografía que se produjeron sobre el Nuevo Mundo en esta época se dan en un contexto de abiertas críticas y cuestionamientos a la presencia española en América provenientes del mundo transpirenaico ${ }^{17}$ que era necesario desmentir. De este modo se entiende, por ejemplo, la Historia del Nuevo Mundo de Juan Bautista Muñoz, escrita "para la instruccion común, para el esplendor de la nacion, para la luz y desengaño general de la república literaria” (1793, p. 1).

De este modo, el fenómeno de reconocimiento de la naturaleza, la sociedad y la cultura americana realizada entre las últimas décadas del siglo XVIII y la primera década del siglo XIX puede estudiarse dejando de lado abordajes del tipo centro-periferia (metrópoli-colonia, Europa-América, etcétera) y renunciando a entender a los actores americanos como meros reproductores de prácticas exóticas o a abordarlos como si actuasen solo en función de las necesidades de la Corona. Los letrados americanos también trabajaron en brindar una imagen de sus ciudades que contradijera el atraso señalado desde fuera del imperio. La mayor parte de los escritos de Araujo a los que se ha hecho referencia estaban relacionados con este esfuerzo. Pero también en estos textos se perciben tensiones locales: se encuentran cruces de intereses entre diferentes sujetos, intenciones de proyectar imágenes que permitan a algunos individuos obtener prestigio o alcanzar lugares de privilegio en el ordenamiento social y también se observan tensiones en el propio reordenamiento de las ciudades en una época de reformas en el recientemente creado Virreinato del Río de la Plata.

Es en este contexto en el que Segurola y Araujo comenzaron sus colecciones. Aunque después de 1810 estas comenzarían a satisfacer otras demandas que surgieron con los cambios políticos, dotándolas de nuevas pragmáticas. El resguardo de papeles está inicialmente emparentado con lo que actualmente se denominaría gobierno o administración. En el Antiguo Régimen la decisión de conservar materiales en el archivo "se realiza [...] como un acto de conservación de hechos o acciones para la memoria (contra el olvido)". Ese acto, inicialmente tiene como objetivo "arreglar posibles conflictos y pleitos futuros" (Zermeño Padilla, 2012, p. 16). Con el correr de los siglos XVIII y XIX el archivo fue mutando su pragmática. Esos papeles acumulados en espacios de poder comenzaron a verse como posibles espejos de un pasado del que ya no se guardaba memoria y del que no había representaciones fiables.

Crónicas e historias pasaron a estar cuestionados. Era necesaria una reconstrucción, como se ha señalado, en un contexto epistemológico en el que el empirismo estaba dotado de una centralidad incuestionada. El archivo comenzó a estar ligado con la historia (Zermeño Padilla 2012, p. 15) ya que apareció como el único lugar posible para tener una experiencia replicable por otros con el pasado, transitando desde el espacio de la legalidad al espacio del saber. Segurola, como coleccionista de documentos, es un gran ejemplo de este paso: su selección de papeles de la esfera de la monarquía (Reales Cédulas, informes, padrones, mapas, etc.) es trasladada al gabinete para su estudio, de manera análoga a la labor del naturalista que establece taxonomías de insectos, aves o minerales que recolecta de la naturaleza.

Con la formación de los Estados (y sus archivos, ya formados para historiadores y sus labores) se distinguirá más acentuadamente entre el archivo público y el privado, inclinándose la balanza hacia el sector público como el depositario más legítimo de los documentos (Podgorny, 2011b). Cuando Segurola 
murió, por ejemplo, sus posesiones van a ser legadas por sus herederos al Estado (en este caso provincial, ya que el presbítero falleció en 1854, cuando Buenos Aires y la Confederación Argentina eran dos Estados independientes uno del otro). En el momento de la donación ocurrió una operación interesante: los objetos fueron clasificados entre papeles, con destino a la biblioteca y otros objetos, destinados al museo. Entonces la colección como unidad se rompió y se la dotó de un criterio totalmente diferente ${ }^{18}$.

Cuando Segurola y Araujo comenzaron con sus colecciones en la primera mitad del siglo XIX no existía una taxonomía de saberes como en la segunda mitad del mismo siglo, por lo que los intereses de curiosos incluían objetos de la más variada índole. Dicho de otro modo: estos acumulaban tal variedad de objetos en una misma colección que no nos permite pensar a sus papeles como un archivo en el sentido contemporáneo del término. Lo que se mantuvo inalterado durante todo el siglo es el lugar asignado al documento: era una puerta de entrada a un tiempo de otro modo inaccesible. La historia había sufrido un quiebre a mediados del siglo XVIII: sus dominios se ampliaron y se volverá una herramienta ineludible. A ambos lados del Atlántico será concebida como una magistra vitae y era necesario recuperarla. $Y$ esa indagación solo era posible desde los papeles transformados en documentos.

Las colecciones se formaban con ese objetivo de acceder al pasado, por lo que en el paso del siglo XVIII al XIX se inaugurará una etapa de búsqueda, recolección y tráfico de documentos. Muchos viajeros indagaron archivos de diversas latitudes e incluso la Corona impulsó la recolección documental. Del mismo modo que propiciaron que los funcionarios asentados en América o los viajeros que recorrían el Nuevo Mundo envíen remesas de especies animales y vegetales o ejemplos minerales para los museos de historia natural, jardines botánicos o bestiarios (De Mello Pereira, 2013), desde la Península se interesaban por los papeles del pasado ibérico y americano. Un ejemplo de esta reunión de materiales desde la Península lo representa el caso de Juan Bautista Muñoz. Interesado en ofrecer una visión diferente sobre la historia del Nuevo Mundo el erudito valenciano se abocó a la reunión de materiales para la escritura de una historia del Nuevo Mundo que permitiera reivindicar el accionar español en la Conquista, fuertemente criticado por William Robertson, Cornelius de Pauw y Guillaume-Thomas Raynal. Solo a partir de los documentos auténticos se podría escribir, según Muñoz, la verdadera historia de Indias. El esfuerzo coleccionista de este actor, redundaría en ciento cuarenta y ocho volúmenes de documentos e, incluso, sería el puntapié inicial de la creación del Archivo de Indias (Cañizares Esguerra, 2007, p. 345).

Este tipo de iniciativas impulsarían diversas empresas de recolección de materiales, como la promovida por Manuel Abella $(1795)^{19}$. En su texto titulado Noticia y plan de un viage para reconocer archivos y formar la coleccion diplomática de España este letrado escribe que "la renovación de las letras desterró el gusto de las fábulas" y a partir de allí "los sabios de todos los pueblos se dedicaron á desenterrar las antiguas memorias que yacían sepultadas entre el polvo y polilla de las bibliotecas, ó entre las ruinas de los antiguos edificios" (1795, p. 3). Más adelante intentará - buscando justificar su empresa- hacer una fundamentación del uso de la fuente documental. Considerará que muchos se habían apurado a escribir historia sin tener el material necesario y ese hecho cimentaba las disputas sobre el pasado existentes: "Después de muchas reflexiones, he hallado que el origen de tanta discordia no es otro, que el de haberse empeñado los Escritores en un trabajo para el qual no estaban hechos los acopios necesarios" (1795, p. 39).

En todo el Imperio español, entonces, proliferaba la práctica de recolectar documentos. $Y$ en un contexto donde las fronteras de lo público y lo privado eran más difusas que cien años más tarde era esperable que muchos documentos terminasen en manos de sujetos interesados en ellos como Segurola y Araujo. Al respecto señala Irina Podgorny que "viajar también significaba visitar las colecciones locales, los museos y los archivos para comprar, copiar, encargar copias, hacer extractos o, aún más fácil, robar los manuscritos que allí se localizaran" (Podgorny 2011 a, p. 49).

Sobre el origen de los materiales en la colección de Araujo y Segurola estos podrían provenir de los fondos jesuíticos, dispersados tras la expulsión de la Compañía en 1767 (Sabor, 1995, p. 49) y también de papeles provenientes de las comisiones demarcadoras: en el catálogo de la colección de Segurola figuran muchos 
mapas y manuscritos autógrafos producidos por sus miembros, a los que seguramente accedió mediante la compra o el intercambio. La acumulación de materiales en las colecciones privadas, por lo tanto, no era una práctica mirada con malos ojos en el período de transición entre el siglo XVIII y XIX, ya que se permitió (o no se impidió) que esos documentos quedaran fuera del resguardo de la monarquía. Este aspecto comenzaría a revertirse hacia mediados del mismo siglo con el celo que los Estados guardaron por los archivos públicos y por el impulso dado a su ampliación (Wasserman, 2008; Podgorny, 2011b).

Si se tiene en cuenta la renuencia de Segurola a publicar sus escritos, se puede pensar que su colección no solo buscaba abastecer la producción de representaciones del pasado. Es lícito creer que Segurola perseguía, a partir de sus posesiones materiales, proyectar una imagen de sí mismo de clérigo ilustrado, de modo análogo a lo que intentó Gregorio Funes en el mismo período (Lida, 2006). A juzgar por ello, es plausible pensar que el cargo de bibliotecario de la Biblioteca Pública de Buenos Aires se le haya otorgado a Segurola a partir de la notoriedad que le daba su biblioteca particular.

Roberto Di Stéfano (2001) estudió las bibliotecas del clero secular rioplatense y entre las bibliotecas más voluminosas de principios del siglo XIX no se encuentra mencionada la de Segurola, aunque es probable que se deba a que este historiador analizó inventarios testamentarios producidos en este período y la muerte del clérigo llegaría más tarde en el siglo. Si bien, entonces, no se cuenta con el dato cuantitativo, sí se puede inferir que la calidad de material que poseía Segurola era relevante para la época, debido a los pedidos de préstamos de libros que recibía. Segurola, como se ha mencionado, era un letrado de Antiguo Régimen, en donde todavía encontraba un lugar central el donativo. Su actividad como lector es típica de la Ilustración: lee, apunta, clasifica, ordena, al modo enciclopedista. Así organizó los escritos que denominó "fruto de mis lecturas”, en los que dejó evidencias de su abordaje de los libros. De ese mismo modo organizó también su colección de manuscritos y copias cuidadosamente catalogados en orden cronológico ${ }^{20}$.

Como se señaló, no es posible separar las posesiones del clérigo entre gabinete, museo, biblioteca y archivo. Pero la colección de Segurola se transformará a medida que esas categorías vayan tomando forma. Eso ocurrirá a lo largo de la vida del canónigo, aunque no por su propia iniciativa, e incluso se concluirá tras su muerte. Si bien, a diferencia de Araujo, en el caso de Segurola no se encuentran representaciones de la historia, sí se puede entender su práctica a partir de la irrupción del empirismo como un nuevo modo de enfrentarse a las cosas.

La modernidad no inauguró en Hispanoamérica nuevas experiencias ${ }^{21}$ temporales, al menos hasta que los cambios políticos que se sucedieron a partir de 1808 obligaron a los letrados a mirar el pasado y transformar a la historia en un concepto político (Zermeño Padilla, 2008, p. 9). Hasta ese momento, tanto en la monarquía española como en la portuguesa la mirada de la historia se realizaba con una perspectiva de futuro, "pero ese futuro se piensa más en términos de conservación y prolongación, no tanto de su transformación” (2008, p. 5). Es en ese marco de recuperación del pasado que Segurola y Araujo inscriben su irrupción en las prácticas de recolección documental y las representaciones del pasado asociadas a ellas ${ }^{22}$. Su relación con el pasado es la de letrados de Antiguo Régimen en transición. Y a diferencia de otros -como Gregorio Funes- no encontrarían una inserción en la elaboración de los nuevos "artefactos literarios propios de la sociedad en la que vivían” (Lempérière, 2008, p. 242), es decir, aquellos que se demandaron tras el derrumbe de la monarquía para la legitimación de las nuevas configuraciones políticas. Si bien ambos letrados continuarán activamente insertos en la vida pública de Buenos Aires después de 1810, lo harán como actores secundarios, prestando auxilio a otros más visibles, dispuestos (o capacitados) para brindar respuestas a la demanda de esa historia que, como señala Wasserman, también fue transformada en el Río de la Plata en concepto político (2010, pp. 22-24). 


\section{A modo de Cierre. De la afirmación del Imperio a la del Estado Nación}

Son discernibles dos momentos de las colecciones documentales estudiadas, separados por el inicio del proceso independentista. Hasta 1810 el impulso coleccionista intentaba aportar elementos para justificar la presencia española (y sus derechos) en América respecto de las disputas con otros imperios europeos. También conocer el pasado de las ciudades de la zona, ya que este tenía claras implicancias jurídicas en el reordenamiento que la región estaba atravesando en el marco de las reformas dieciochescas. Por último, brindar elementos para sustentar la pertenencia de las ciudades americanas a la cultura europea, desmintiendo a diversos críticos. Además es presumible un genuino interés proveniente del terreno de la curiosidad por parte de los actores.

Estas colecciones se resignificarían con el período de revolución y guerra iniciado en la segunda década del siglo, por lo que pasarían a aportar elementos para la justificación de la ruptura con el monarca. En ese momento el apego a los documentos para las representaciones del pasado se acoplará a las renovadas nociones de la temporalidad: 1810 introducirá la idea de que se estaba viviendo un tiempo nuevo y la historia como magistra vitae mutará en otra que intentará marcar sus diferencias con el pasado (Wasserman, 2015, p. 6). Como se mencionó, estos letrados no logran insertarse plenamente en el contexto discursivo cambiante, sobre todo en el caso de Araujo, quien tras 1810 no volvería a publicar textos sobre el pasado y moriría en 1835 en el momento en que trabajaba en la ampliación de su Guí (Quesada, 1864, p. 457), un texto que resultaba, en ese entonces, epistemológicamente anacrónico.

Por lo tanto, las nuevas historias saldrían de otras plumas, como la de Gregorio Funes. Sin embargo, fueron letrados como Segurola y Araujo los que marcan el tránsito entre dos paradigmas diferentes en el abordaje de los vestigios escritos del pasado. Es a partir de ellos que el documento comienza a transformarse en ineludible para las representaciones de la historia y, por consiguiente, estos actores representan el eslabón que une la guarda de documentación en las instituciones de la monarquía con fines gubernamentales o jurídicos con los criterios decimonónicos de archivística para la producción de saberes históricos (Podgorny, 2011b).

En la segunda mitad del siglo XIX se comenzó a observar con detenimiento el accionar de estos y otros coleccionistas: ante la dispersión de los archivos era necesario reconstituirlos para que el "historiador futuro" pudiera escribir la historia nacional y, por otro lado, pudieran encontrarse elementos para la delimitación de las fronteras en disputa de los nuevos Estados que surgieron de la ruptura de los Imperios Ibéricos. Es por ello que Manuel Trelles, quien sería uno de los actores que más trabajó en el ordenamiento y recopilación documental en el Archivo General de Buenos Aires con estos fines (incluso promoviendo expediciones a los archivos europeos para la reunión de materiales) prestará atención a los coleccionistas particulares. En ese sentido resultaban clave los materiales reunidos por sujetos como Segurola y Araujo.

Las colecciones y bibliotecas privadas en el Río de la Plata en muchas ocasiones han sufrido la dispersión (por ventas, remates o hurtos) y la pérdida. En otros casos estas acabaron engrosando las colecciones del Estado (en archivos y bibliotecas públicas). La colección de Segurola, como se ha señalado, terminó depositada en la Biblioteca Nacional tras la muerte del clérigo, aunque algunos de sus materiales se encuentran entre las colecciones del Museo Mitre; el destino de los papeles que coleccionó José Joaquín de Araujo es más nebuloso, y según Vicente Quesada, tal vez se hayan perdido (1864, p. 457). Aunque otra posibilidad es que se hayan incorporado a la colección de Pedro de Angelis, quien en la década de 1830 era el más importante coleccionista de Buenos Aires y adquiría materiales de diferentes maneras, entre ellas, la compra a herederos de eruditos coleccionistas (Sabor, 1995, pp. 160-161). El napolitano menciona en su Colección haber tomado contacto con la biblioteca de Araujo tras su muerte a través de sus deudos, aunque no menciona apropiación alguna de material, como sí se tiene constancia de que de Angelis compró a Araujo algunas de sus monedas (Sabor, 1995, p. 80). Incluso es posible que el propio Segurola, que sobrevivió casi veinte años a Araujo, se haya hecho de alguno de sus materiales. 


\section{REFERENCIAS BIBLIOGRÁFICAS}

Abella, M. (1795) Noticia y plan de un viagepara reconocer archivos y formar la coleccion diplomática de España. Madrid: Imprenta Real.

Araujo, J. (10 de enero de 1802) Examen crítico de la época de la fundación de Buenos Ayres promovido por el memorial de Enio Tullio Grope, que se haya en el segundo tomo del Telégrafo. Telégrafo Mercantil, 3(2)

Araujo, J. (1803) Guia de forasteros del Virreinato de Buenos-Ayres para el año de 1803. Buenos Aires: Imprenta de los Niños Expósitos.

Araujo, J. (1807) Adiciones y correcciones a la dedicatoria que el autor del romance heroyco sobre la Reconquista de BuenosAyres hizo al M.I. Cabildo. Buenos Aires: Imprenta de los Niños Expósitos

Biblioteca Nacional (1940) Revista de la Biblioteca Nacional. Buenos Aires: Imprenta de la Biblioteca Nacional.

Biblioteca Nacional (1944) Archivo del doctor Gregorio Funes, Deán de la Santa Iglesia Catedral de Córdoba (tom.1). Buenos Aires: Imprenta de la Biblioteca Nacional.

Brading, D. (2015) Orbe indiano. México: Fondo de Cultura Económica.

Cañizares Esguerra, J. (2007) Cómo escribir la historia del Nuevo Mundo. Historiografías, epistemologías e identidades en el mundo del Atlántico del siglo XVIII. Ciudad de México: Fondo de Cultura Económica.

Carbia, R. (1921) El Dean Funes plagiario (Valoración crítica de su "Ensayo Histórico"). Humanidades, 1, 367-374.

Carbia, R. (1939) Historia crítica de la historiografía argentina. La Plata: Facultad de Humanidades y Ciencias de la Educación de la Universidad de La Plata.

Cardim, P., Herzog, T., Ruiz Ibáñez, J. y Sabatini, G. (2012) Introduction, en Cardim, P.; Herzog, T.; Ruiz Ibáñez, J. y Sabatini, G. (eds.), Polycentric monarchies. How did Early Modern Spain and Portugal achieve and maintain a global hegemony? Brighton, Portland, Toronto: Sussex Academic Press.

Correa Luna, C. (5 de mayo 1935) José Joaquín de Araujo, historiador colonial y patriarca de los periodistas argentinos, a los cien años de su fallecimiento. La Prensa, p. 2.

Cutolo, V. (1968) Nuevo diccionario biográfico argentino (vol. I). Buenos Aires: Elche.

De Asúa, M. (2010) La ciencia de Mayo. La cultura cientifica en el Río de la Plata, 1800-1820. Buenos Aires: Fondo de Cultura Económica.

De Angelis, P. (1836) Colección de obras y documentos relativos a la historia antigua y moderna de las Provincias del Río de la Plata. Buenos Aires: Imprenta del Estado.

De Mello Pereira, Magnus Roberto (2013). "Las cosas singulares de piedras, animales, plantas": la formación y el funcionamiento de la red imperial española de remesas científicas en el Río de la Plata". Anais do Mueseu Paulista, 1.

Del Portillo, E. (5 de septiembre de 1801) Memorial de la M.N. y M.L. Ciudad de Buenos Ayres, sobre que en los Almanakes, y otros documentos donde se está cometiendo el anacronismo de establecer la época de la fundación de esta Metropoli en el año de la era vulgar de 1536 se subrogue en el de 1575 que fue cuando realmente se verifico. Telégrafo Mercantil, 2(11).

Di Stéfano, R. (2001). Religión y cultura: libros, bibliotecas y lecturas del clero secular rioplatense (1767-1840). Bulletin Hispanique, 103(2), 511-541.

Esteve Barba, F. (1964) Historiografía indiana. Buenos Aires: Gredos.

Foucault, M. (2015) Les mots et les choses. Paris, Gallimard.

Funes, G. (20 de junio 1802). Carta crítica sobre la relación histórica de la Ciudad de Córdoba que hizo S. M. I. Ayuntamiento, y se publicó en el Telegrafo Argentino N.4. Tom. III. Telégrafo Mercantil, 4(8).

Funes, G. (1856). Ensayo de la historia civil de Buenos Aires, Tucumán y Paraguay (2a ed.). Buenos Aires: Imprenta Bonaerense.

Furlong, G. (1969) Historia social y cultural del Río de la Plata, 1536-1810: el trasplante cultural. Buenos Aires: Tipográfica Editora Argentina. 
García Cuadrado, A. (1999). Acerca de un plan de viaje de 1795 para reconocer archivos. Boletín de la ANABAD, 49(2) García de Loydi, L (1994). Canónigo Doctor Saturnino Segurola. Buenos Aires: Ed. Braga-Junta de Historia Eclesiástica Argentina.

Gentinetta, M. (2012) La disciplina botánica en las expediciones ilustradas por la América Meridional austral en la segunda mitad del siglo XVIII y sus aportes a las políticas borbónicas. Anuario de la Escuela de Historia Virtual, 3.

González Bernaldo, P. (1991). La Revolución Francesa y la emergencia de nuevas prácticas de la política: la irrupción de la sociabilidad política en el Río de la Plata revolucionario (1810-1815). Boletín del Instituto de Historia Argentina y Americana "Dr. Emilio Ravignani", 3(3).

González Cruz, D. (2017). El tratamiento de la historia en los periódicos de la América hispana (1722-1802).E-Spania, 26.

Halperin Donghi, T. (2013) Letrados y pensadores. El perfilamiento del intelectual hispanoamericano en el siglo XIX. Buenos Aires: Emecé.

Koselleck, R. (2007). Crítica y crisis. Un estudio sobre la patogénesis del mundo burgués. Madrid: Trotta.

Lempérière, A. (2008). Los hombres de letras hispanoamericanos y el proceso de secularización (1800-1850). En Altamirano, C. (dir.). Historia de los intelectuales en América Latina. Buenos Aires: Katz.

Lida, M. (2006). Dos ciudades y un deán. Biografia de Gregorio Funes, 1749-1829. Buenos Aires: Eudeba.

Martini, M. (1998) Francisco Antonio Cabello y Mesa, un publicista ilustrado de dos mundos. Buenos Aires: Instituto de Investigaciones sobre Identidad Cultural - Universidad del Salvador.

Mazin, O. (2008). Gente de saber en los virreinatos de Hispanoamérica. En Altamirano, C. (dir.). Historia de los intelectuales en América Latina. Buenos Aires: Katz.

Muñoz, J. (1793). Historia del Nuevo-Mundo. Madrid: Viuda de Ibarra.

Nieto Olarte, M. (2003). Historia Natural y la apropiación del Nuevo Mundo en la Ilustración española. Bulletin de l'Institut français d'études andines, 32, 417-429.

Ortiz Gambetta, E. (2018). Textos permeables: archivo colonial, prensa y literatura en el Río de la Plata. Universum, $33(1)$

Parish, W. (1838) Buenos Ayres and the Provinces of the Rio de la Plata: their present state, trade and debt. Londres: John Murray.

Parish, W. (1852) Buenos Ayres and the Provinces of the Rio de la Plata: from their discovery and conquest by the spaniards to the establishment of their political independence. Londres: John Murray.

Parish, W. (1852b) Buenos Aires y las Provincias del Rio de la Plata (trad. Justo Maeso). Buenos Aires: Benito Hortelano.

Penhos, M. (2005). Ver, conocer, dominar. Imágenes de Sudamérica a fines del siglo XVIII. Buenos Aires: Siglo XXI.

Podgorny, I. (2011a) Las rutas del saber. El tráfico de manuscritos iberoamericanos en la primera mitad del siglo XIX. En M. Lopes y A. Heizer (coor.) Colecionismos, práticas de campo e representaçôes. Campina Grande: EDUEPB.

Podgorny, I. (2011b) Fronteras de papel: archivos, colecciones y la cuestión de límites en las naciones americanas. Historia critica, 44, 56-79.

Podgorny, I. (2013) La febbre dei fossili. Pedro de Angelis y el carácter transaccional de la ciencia. Zama, 5, 11-26.

Puig-Samper, M. (2011). Las expediciones científicas españolas en el siglo XVIII. Canelobre. Revista del Instituto Alicantino de Cultura Juan Gil-Albert, n.57, 20-41.

Quesada, V. (1864) Escritos póstumos del señor José Joaquín de Araujo. La revista de Buenos Aires, 2(16).

Real Academia Española (1780) Diccionario de la lengua castellana. Madrid: Joaquín Ibarra.

Romero, J. (2014) Latinoamérica: las ciudades y las ideas. Buenos Aires: Siglo XXI.

Sabor, J. (1995) Pedro de Angelis y los origenes de la bibliografia argentina. Buenos Aires: Solar.

Shapin, S. y Schaffer, S. (2005) El Leviathan y la bomba de vacio. Hobbes, Boyle y la vida experimental. Bernal: Universidad Nacional de Quilmes.

Torre Revello, J. (1940) El libro, la imprenta y el periodismo en América. Buenos Aires: Peuser. 
Trelles, M. (1863). Apuntes y documentos para la historia del puerto de Buenos Aires. La revista de Buenos Aires, 1(1), 9-28.

Vallejos, P. (2013) La construcción retórica de los primeros estudios históricos en la Argentina. African Yearbook of Rhetoric, 4(2), 161-174.

Wasserman, F. (2008) Entre Clío y la polis. Buenos Aires, Teseo.

Wasserman, F. (2010) La historia como concepto y como práctica: conocimiento histórico en el Río de la Plata (1780-1840). História da historiografía, 4.

Wasserman, F. (2016) Experiencias de tiempo y cambio conceptual en el proceso revolucionario rioplatense (1780-1840).e-@latina, 14(54)

Zermeño Padilla, G. (2008) Historia, experiencia y modernidad en Iberoamérica, 1750-1850. Jahrbuch für Geschichte Lateinamerikas, 45, 113-148.

Zermeño Padilla, G. (2012) De viaje tras el encuentro entre archivo e historiografía. Historia y grafía, 38.

\section{Notas}

1 Para un acercamiento a los itinerarios vitales de estos dos letrados pueden consultarse: sobre Saturnino Segurola la biografía de Ludovico García de Loydi (1994) además de algunas reseñas biográficas como la que se incluye en la Revista de la Biblioteca Nacional (1940, 5-8); sobre José Joaquín de Araujo puede observarse la entrada en el Nuevo diccionario biográfico argentino de Vicente Cutolo (1968, 199-200), el artículo que sobre él publicó Carlos Correa Luna (1935) y los comentarios sobre su trayectoria escritos por Vicente Quesada en la Revista de Buenos Aires (1864).

2 La noción de crítica que se adopta es la propuesta por Reinhart Koselleck (2007). La crítica, desde la cultura dieciochesca, ocupa el lugar de "tribunal moral" en el que los actores juzgan lo dicho por otros a partir de valores como la verdad o la licitud. Sin considerar a los diccionarios como depositarios de conceptos utilizados del mismo modo por todos los hablantes de una lengua, es interesante observar la edición de 1780 del diccionario de la Real Academia Española para verificar que la noción en el mundo de habla castellana del término crítica es similar a la que Koselleck describe para el mundo germano hablante. Allí crítica se define como "El arte, ó facultad de juzgar rectamente": el adverbio de la frase nos indica el carácter moral que la crítica poseía en el mundo iberoamericano entre el siglo XVIII y principios del siglo XIX.

3 Una visión diferente sobre esta práctica es la que ofrece Eugenia Ortiz Gambetta (2018, p. 224): “el archivo no se recuperó para legitimar los propios usos, como antecedentes prestigiosos, sino para mostrar las cualidades de un presente virtuoso que contrastaba con la oscuridad de origen de esos documentos".

4 Sobre esta intervención de Gregorio Funes en el Telégrafo Mercantil puede consultarse Halperin Donghi (2013), Lida (2006), Martini (1998), Torre Revello (1940), Vallejos (2013). Tulio Halperin Donghi y Miranda Lida profundizan en las intencionalidades de Funes en su publicación.

5 La historia natural en este período consistía en un área del saber en el que se planteaba como objetivo el reducir simbólicamente todo lo existente en el mundo natural a categorías ininteligibles para la humanidad. Para ello, luego de explorar e identificar especies, los naturalistas practicaban el método taxonómico, es decir, la clasificación y el ordenamiento de las diversas especies animales, vegetales o minerales a partir de sus características observables. Del naturalismo provienen, por ejemplo, las ideas de "reino vegetal" o "reino animal" o la taxonomía de elementos químicos de Antoine Lavoisier. Para un acercamiento al saber naturalista en los siglos XVIII y XIX pueden consultarse algunos de los trabajos citados en este artículo: De Asúa (2010), Foucault (2015), Gentinetta (2012), Nieto Olarte (2003), Penhos (2005).

6 Es destacable el surgimiento en el siglo XVIII de letrados interesados en los vestigios materiales para la reconstrucción del pasado. Este fenómeno será más frecuente en aquellas áreas donde las culturas prehispánicas despertaban un interés mayor. De todos modos las colecciones de Segurola y Araujo incluían todo tipo de objetos, más allá de los documentos, entre los que las monedas eran centrales.

7 De todas las fuentes mencionadas en este trabajo, este almanaque es el único que parece haberse perdido.

8 Es importante señalar que la Guia de forasteros (como todos las publicaciones de Araujo) se imprimieron anónimas o con seudónimo. Pero son numerosas las voces que asignan a Araujo la autoría de estos escritos. De hecho, este reconocimiento parte desde la propia pluma de Funes y de otros contemporáneos de Araujo que desde el siglo XIX mencionan al funcionario como el autor de estas obras.

9 El hecho de que Funes mencione deliberadamente a Segurola y a Araujo en su trabajo (como a otros colaboradores: Bartolomé Muñoz y Gregorio Tadeo de la Cerda), puede tener que ver con que sus relaciones personales lo obligaran a hacerlo. El primero era un colega en la carrera eclesiástica, con el segundo guardaba relación desde principios de 
siglo. En carta a Gregorio Funes fechada en junio de 1802 Araujo escribe, elogiosamente, "Dichoso yo si con el tiempo puedo decir, q.e el todo de mi ilustración lo debo á la fina correspond.a con el S.or D.r D.n Gregorio Funes” (cit. en Biblioteca Nacional, 1944, p. 82). En esa misma carta, como también ha señalado Mónica Martini (1998, pp. 168-169), se menciona la colaboración de Araujo en la facilitación de los vínculos que permitieron a Funes publicar aquella "Carta crítica” (1802) sobre la fecha de la fundación de Córdoba que publicara bajo el seudónimo de Patricio Saliano. Ambos letrados, incluso, publicaron sus textos en el Telégrafo Mercantil bajo un seudónimo similar, ya que Araujo utilizaba el de "Patricio de Buenos Ayres".

10 Sobre esta Colección véanse los capítulos 6 y 7 del libro de Josefa Sabor Pedro de Angelis y los origenes de la bibliografía argentina (1995) y sobre las fuentes consultadas por de Angelis véanse las páginas 311 y 312 del mismo trabajo.

11 En la Colección de Pedro de Angelis, Araujo es mencionado una sola vez. En esa mención se deja constancia de que en su biblioteca existía un ejemplar de la Historia del Paraguay del jesuita Guevara, aunque de Angelis reprodujera la copia de Segurola. De todos modos es importante señalar que Araujo murió un año antes de que el napolitano comenzara su recolección de materiales para la Colección.

12 Se interpreta "MS" como "mister Segurola”. Un párrafo antes Parish, luego de mencionar la colaboración del clérigo y de sus aportes a la obra de Gregorio Funes, menciona la "valuable collection of MSS", es decir, "Mister Saturnino Segurola”.

13 Esta sigla no aparece en la traducción porteña de Justo Maeso (Parish, 1852b).

14 Para una caracterización general de estas expediciones véase Puig-Samper (2011)

15 Es posible consultar este inventario en la Revista de la Biblioteca Nacional (1940, pp. 15-73)

16 Para una aproximación a esta perspectiva, véase Cardim, P., Herzog, T., Ruiz Ibáñez, J. y Sabatini, G. (2012).

17 En Europa, a lo largo del siglo XVIII, surgieron cuantiosas críticas al accionar español en América en el contexto de las diversas pujas que se produjeron entre algunas monarquías por controlar o intervenir en el Nuevo Mundo. Una de ellas se plasmó en un texto de historia que, curiosamente, obtuvo una inicial recepción elogiosa en España: la History of America de William Robertson. De hecho, fue autorizada una traducción de este trabajo en Madrid. En esta caracterización crítica de América acompañaron a Robertson otros como Guillaume-Thomas Raynal y Cornelius de Pauw. Posteriormente surgieron voces que intentaron presentar respuestas a estos escritores: entre estos se encuentra, por ejemplo, a Juan Bautista Muñoz, a las mencionadas expediciones naturalistas de Félix Azara y Alejandro Malaspina y a letrados americanos como Segurola y Araujo, entre otros provenientes de toda la América Hispana. Existen diversos estudios de este fenómeno. A nuestro juicio los más destacados, en cuanto a los usos del pasado en este contexto discursivo, son la segunda parte de Orbe indiano de David Brading (2015) y Cómo escribir la historia del Nuevo Mundo de Jorge Cañizares Esguerra (2007)

18 En carta al ministro de gobierno Irineo Portela, Carlos Tejedor, director de la Biblioteca Pública de Buenos Aires en ese momento, señala que "han venido muchas cosas cuyo destino natural no es esta biblioteca, sino el museo" (cit. en Biblioteca Nacional, 1940, p. 12)

19 Sobre este plan, véase García Cuadrado (1999)

20 Ese catálogo realizado por Segurola se encuentra en el repositorio del Museo Mitre.

21 En este trabajo asumimos una noción de "experiencia” diferente a la adoptada por Zermeño Padilla en el texto citado. El historiador mexicano, apoyándose en la propuesta conceptual de Reinhart Koselleck, refiere a la relación de los actores con la temporalidad y no a las prácticas empíricas en las representaciones del pasado que se analiza en este trabajo.

$22 \mathrm{Al}$ respecto escribió Araujo: "el testigo de los tiempos, la luz de la verdad, la vida de la memoria, la escuela de la vida, la mensagera de la antiguedad esto es la Historia” (1802, p. 19). 